\title{
CONTROLE DE ESTOQUES COMO DIFERENCIAL ESTRATÉGICO: UMA ANÁLISE BIBLIOMÉTRICA POR MEIO DO PROKNOW-C
}

\author{
INVENTORY CONTROL AS A STRATEGIC DIFFERENTIAL: A BIBLIOMETRIC ANALYSIS \\ THROUGH PROKNOW-C
}
Carina Giacomin ${ }^{1}$, Thiara Cezana Gomes ${ }^{2}, \&$ Marcos Wagner Jesus Servare Junior ${ }^{3 *}$
${ }^{123}$ Centro Universitário Salesiano - UniSales.
${ }^{1}$ carinagiacomin@outlook.com ${ }^{2}$ thiaracezana@gmail.com ${ }^{3}$ marcos.servare@ salesiano.br

\section{ARTIGO INFO.}

\section{Recebido em: 07.06.2021}

Aprovado em: 07.07.2021

Disponibilizado em: 12.07.2021

\section{Palavras-chave:}

Gestão de Estoque; ProKnow-C; Diferencial Estratégico.

\section{KEYWORDS:}

Inventory Management; ProKnow-C; Strategic Differential.

\footnotetext{
*Autor Correspondente: Servare Junior, M. W. J.
}

\section{RESUMO}

O presente estudo tem como objetivo geral analisar o portfólio bibliográfico encontrado por meio do método ProKnow-C, o qual traz artigos relevantes referentes ao tema: Controle de estoque como diferencial estratégico. O método ProKnow-C trata-se de uma análise quantitativa de artigos publicados feita através de filtros como a leitura de partes e integralidade do texto e a quantidade de citações que consta no Google Scholar, entre outros. A partir desse estudo, identificou-se 16 artigos que compõem o portfólio bibliográfico, onde foram observados nestes trabalhos os autores de destaque, os meios de publicação de destaque, o material que serviu como base para os trabalhos, além de apontadas as contribuições de cada um deles.

\begin{abstract}
This study has as general objective to analyze the bibliographic portfolio found through the ProKnow-C method, which brings relevant articles related to the theme: Inventory control as a strategic differential. The ProKnow-C method is a quantitative analysis of published articles made through filters such as the reading of parts and completeness of the text and the number of citations that appear in Google Scholar, among others. From this study, 16 papers were identified that make up the bibliographic portfolio, where prominent authors were observed in these works, the prominent means of publication, the material that served as the basis for the works, in addition to pointing out the contributions of each one of them.
\end{abstract}



análise bibliométrica por meio do Proknow-C. Brazilian Journal of Production Engineering, 7(3), 41-55.

\section{INTRODUÇÃO}

Muitas transformações acontecem constantemente no mundo global, na vida dos seres humanos, no âmbito cultural, social, econômico ou tecnológico de uma forma cada vez mais acelerada. Assim, os hábitos e necessidades de consumo são cada vez mais emergenciais, a necessidade do cliente se tornou prioridade na maior parte das empresas do Brasil e do mundo, através da cadeia de suprimentos.

Segundo Vargas, Baccin e Sellitto (2017) com a correta gestão de estoque é possível melhorar os níveis de serviço e o lucro da empresa, minimizando assim seus gastos. A gestão de estoque, de acordo com Lucas, Ferreira, Ribeiro e Gontijo (2018), se tornou fundamental para a sobrevivência de uma empresa, pautada uma eficiente administração nos processos.

O equilíbrio entre os custos e a disponibilidade do produto para com o cliente retorna em uma eficiente gestão de estoque, para que assim sempre tenha o produto quando solicitado (Mantovani, Silva, Pirtouscheg, Pascoal, \& Evangelista, 2020).

Deste modo, esta pesquisa objetiva apresentar uma revisão da literatura, com auxílio do método ProKnow-C, quanto à gestão de estoque como diferencial estratégico em empresas do ramo varejista. De acordo com Lucas et al. (2018), o almoxarifado representa os estoques em um contexto organizacional sendo ele de muita importância para a empresa, podendo agregar economia de custos e até otimizações de processos.

A construção deste trabalho se deu a partir do método ProKnow-C onde obteve-se um portfólio bibliográfico com importante reconhecimento científico. No decorrer do trabalho estão expostas figuras representadas graficamente com informações quantitativas do portfólio bibliográfico.

Desse modo, a justificativa do artigo relaciona-se à necessidade dos pesquisadores em encontrar material com reconhecimento científico. Ela dar-se-á através do método utilizado sistematicamente de grande eficácia.

O artigo é organizado, além desta Introdução, como segue: na Seção 1 tem-se uma breve revisão de literatura relacionada ao tema proposto, controle de estoque como diferencial estratégico; na Seção 2, encontra-se a metodologia aplicada; na Seção 3 são analisados os artigos selecionados e uma análise bibliométrica e sistêmica é apresentada; por fim, na Seção 4 encontram-se as considerações finais.

\section{REVISÃO DE LITERATURA}

Segundo Chopra e Meindl (2003), o papel do estoque em uma empresa é estratégico e possibilita o alcance de maior competitividade, pois se a estratégia competitiva da empresa é manter estoques altos isso exige dos gerentes maior grau de responsabilidade. De acordo com Pozzo (2004), os estoques são suficientes para a determinação de estratégias essas que adequam o correto dimensionamento dos estoques a nível de serviço oferecido aos clientes. Uma empresa bem-sucedida é uma empresa que se mantem atualizada com informações constantes e globais (Lucas et al., 2018). 

análise bibliométrica por meio do Proknow-C. Brazilian Journal of Production Engineering, 7(3), 41-55.

De acordo com Ballou (2001), a manutenção de estoques pode custar entre $20 \%$ e $40 \%$ de seus valores por ano. Segundo Pozzo (2004), os custos são influenciados por diversos fatores como o volume, a disponibilidade, a movimentação, a mão-de-obra e o recurso próprio que depende da situação. Existem três categorias de custos na administração de estoques (Ballou, 1993):

- $\quad$ Os custos de manutenção - são aqueles associados a todos os custos necessários para manter certa quantidade de mercadorias por um período;

- $\quad$ Os custos de requisição ou compra - estão associados ao processo de aquisição das quantidades suficientes para reposição do estoque;

- Os custos de falta de estoques ocorrem quando existem a demanda por um item e o mesmo não está disponível no estoque.

Peluso, Cotrim, Oliveira, Campos e Galdamez (2020) complementam ainda que o controle de estoque é uma função muito importante nas empresas, tendo como resultado maior competitividade, visto que as empresas estão em busca de seu aprimoramento constante para se manterem ativas no mercado atual.

De acordo com Novaes (2001), a formação de estoques pode levar à redução de custos nos seguintes casos:

- $\quad$ Custo de emissão do pedido - quanto maior o estoque, menor a necessidade de reposição do mesmo;

- $\quad$ Custos do stock out - na medida em que não há material (para produção interna ou para venda), é possível incorrer em algumas paradas de produção, vendas perdidas e clientes insatisfeitos;

- Custos de aquisição - pedir lotes maiores gera estoques maiores, mas os custos unitários são menores devido aos descontos por quantidades e aos menores custos de fretes e manuseio;

- $\quad$ Custos da qualidade na partida (start up) - quando um novo lote de produção é iniciado, há chances de perda de produtos devido a falhas no processo.

De acordo com Viana (2002), a gestão de estoques pode e deve ser caracterizada como a relação entre as atividades da organização como um todo, dando total enfoque a atender as necessidades e apresentando maior eficiência com o menor custo possível, contando também com um elevado giro no capital que é investido em matérias primas. Dessa maneira, por meio da análise, pôdese notar que seu objetivo mais importante é proporcionar um melhor equilíbrio entre os estoques e consumo.

Dessa forma, de acordo com Pinto, Tortato, Veiga e Catapan (2013), a filosofia lean é também um dos meios de grande importância para alcançar vantagens competitivas através da gestão de estoque, visto que essa filosofia, se utilizada com todo o potencial das técnicas enxutas, pode proporcionar a redução de custos.

Já os estudos de Ching (2010) apontam que gerir estoques é uma iniciativa para diminuição dos custos totais relacionados à compra e gestão de materiais, levando em consideração que as variadas etapas da gestão de estoque ocorriam habitualmente através de diferentes departamentos. 
Citação (APA): Giacomin, C., Gomes, T. C., \& Servare Junior, M. W. J. (2021). Controle de estoques como diferencial estratégico: uma análise bibliométrica por meio do Proknow-C. Brazilian Journal of Production Engineering, 7(3), 41-55.

Ballou (2009) define que a função do estoque pode minimizar e maximizar diversos fatores. Os fatores podem ser observados no Quadro 1.

Quadro 1. Funções dos estoques segundo Ballou (2009)

\begin{tabular}{|l|l|}
\hline \multicolumn{1}{|c|}{ MINIMIZAR } & \multicolumn{1}{c|}{ MAXIMIZAR } \\
\hline $\begin{array}{l}\text { - Demora ou atraso no fornecimento de materiais; } \\
\text { - Sazonalidade no suprimento; }\end{array}$ & $\begin{array}{l}\text { - Compra ou produção em lotes econômicos; } \\
\text { - Riscos de dificuldade no fornecimento. }\end{array}$ \\
\hline
\end{tabular}

Fonte: Adaptado Ballou (2009).

Com um ótimo controle de estoque, sempre em busca da excelência, a empresa inibe contratempos, por exemplo, não possuir o produto armazenado para entregar para o cliente imediatamente, atrasar entregas, entre outros, evitando, assim, perda de clientes potenciais (Piran, Azzolini, \& Vanin, 2020). Já para Menegat e Borella (2016), a redução de estoque juntamente com a redução de desperdícios é uma grande aliada e resultado do aumento da lucratividade. Assim, a gestão de estoque se torna um atrativo de grande porte quanto à competitividade do mercado dentro da busca pela excelência.

\section{PROKNOW-C: SELEÇÃO DOS ARTIGOS}

Para atingir o objetivo do trabalho, foi utilizado o método Knowledge Development ProcessConstructivist (ProKnow-C) proposto por Ensslin et al. (2010), da qual foi feita a seleção e a análise de artigos para a construção de um portfólio bibliográfico de grande relevância científica.

A princípio, com base no tema escolhido, controle de estoque como diferencial estratégico, foi possível definir a palavra-chave, sendo ela "Controle de Estoque". Com a palavra-chave definida, foi efetuada uma busca analítica nos bancos de dados disponibilizados, dessa maneira seus resultados podem ser observados na Figura 1.

Figura 1. Quantidade de artigos por periódico e congresso

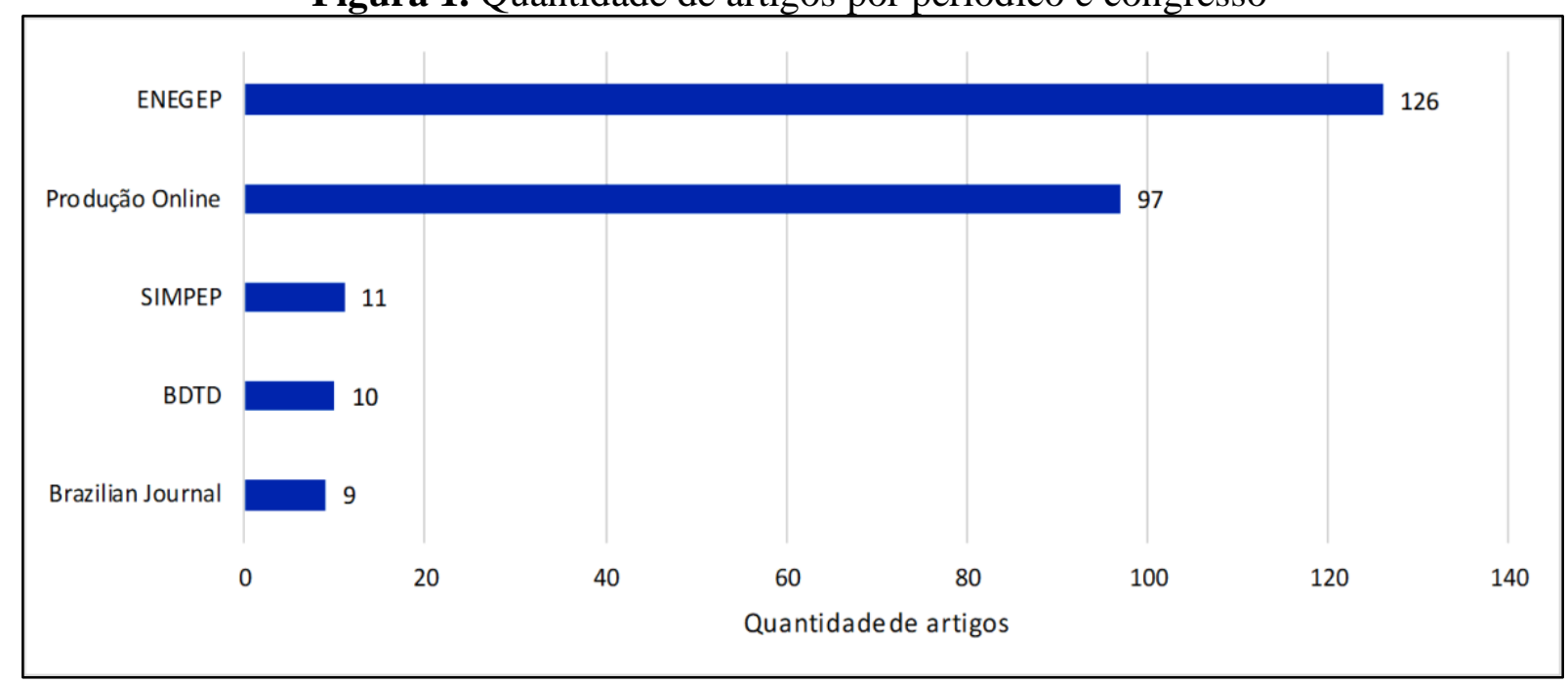

A partir dessa busca nos periódicos da Figura 1, o banco de artigos passou por diversos filtros e avaliações de acordo com o tema proposto (controle de estoque como diferencial estratégico) até chegar no portfólio bibliográfico final. A seguir, delineamento das seis fases de filtragem.

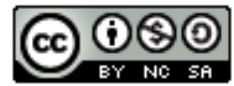



análise bibliométrica por meio do Proknow-C. Brazilian Journal of Production Engineering, 7(3), 41-55.

Fase 1 - Banco de Artigos Brutos: Nessa fase inicial é onde o banco de artigos está em sua forma bruta, sem filtros aplicados e com o total de artigos encontrados na busca, totalizando 253 artigos.

Fase 2 - Banco de Artigos Bruto Não Repetidos: Foi avaliado se no banco de artigos brutos havia artigos repetidos. Visto que não existiam, permaneceu-se com a totalidade de 253 artigos.

Fase 3 - Banco de Artigos Bruto Não Repetidos e com Títulos Alinhados: Nessa fase foi avaliado o título de acordo com o tema, por critério do autor. De 253 artigos, permaneceram 149 artigos.

Fase 4 - Banco de Artigos Bruto Não Repetidos, com Títulos Alinhados e Reconhecimento científico: Essa fase foi a mais importante, onde ocorreram mais exclusões de artigos. Nela foi avaliada a relevância do artigo, conforme quantidade de citações elencada no Google Scholar. Com essa informação disposta, calcula-se o percentual acumulado que os artigos mais citados representam. Sendo assim, foram elegidos os artigos responsáveis por $90 \%$ das citações. Totalizaram 44 artigos.

Fase 5 - Disponibilidade: Foi apurado nessa fase se cada artigo possuía a disponibilidade de visualização do documento por inteiro (fácil acesso para download). Nenhum artigo foi excluído nessa fase, todos foram encontrados por completo sem necessidade de filiações e pagamentos de taxas.

Fase 6 - Alinhamento: Refere-se à verificação do alinhamento do texto completo do artigo em relação ao tema proposto, controle de estoque como diferencial estratégico. Enquanto a Fase 3 afere somente o título, a Fase 6 apura o artigo como um todo. Para isso, realizou-se a leitura completa dos artigos e, ao final, 28 artigos não estavam alinhados por completo ao tema, sendo retirados do banco de artigos. Totalizando finalmente 16 artigos no portfólio bibliográfico.

A Figura 2 ilustra cada uma das fases relatadas anteriormente e o desdobramento da quantidade de artigos conforme inserção de novos filtros.

Figura 2. Fases de filtragem do banco de artigos

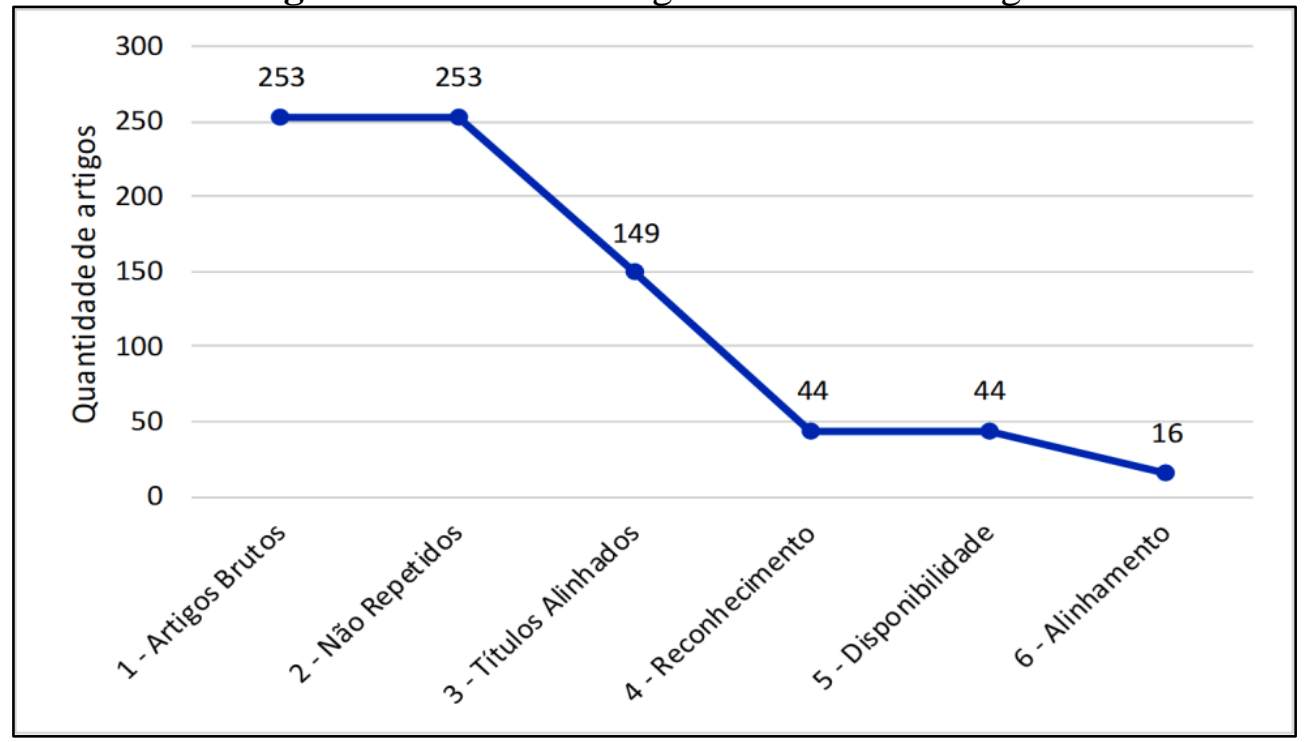

Ao final de todas as fases, obteve-se 16 artigos de relevância no portfólio bibliográfico descrito neste artigo. O Quadro 2 apresenta um resumo dos artigos selecionados, seus respectivos autores, número de citações conforme busca no Google Scholar, ano e periódico, congresso ou simpósio da publicação.

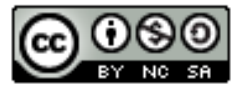


Citação (APA): Giacomin, C., Gomes, T. C., \& Servare Junior, M. W. J. (2021). Controle de estoques como diferencial estratégico: uma análise bibliométrica por meio do Proknow-C. Brazilian Journal of Production Engineering, 7(3), 41-55.

Quadro 2. Portfólio bibliográfico

\begin{tabular}{|c|c|c|c|c|}
\hline Artigo & Autor (es) & Citações & Ano & Periódico \\
\hline $\begin{array}{c}\text { Previsão de demanda e análise } \\
\text { simplificada da gestão de estoque } \\
\text { aplicadas a uma empresa do setor } \\
\text { alimentício }\end{array}$ & $\begin{array}{l}\text { Araújo, G. C., Silva, J. P. } \\
\text { Z., Souza, L. R., Loureiro, } \\
\text { M. B., Feroni, R. C. }\end{array}$ & 10 & 2018 & $\begin{array}{l}\text { Brazilian Journal of } \\
\quad \text { Production } \\
\text { Engineering - BJPE }\end{array}$ \\
\hline $\begin{array}{c}\text { Aplicação da curva abc na gestão de } \\
\text { estoque de uma micro empresa de } \\
\text { Aracaju-SE }\end{array}$ & $\begin{array}{l}\text { Palomino, R., Silveira, R. } \\
\text { O., Oliveira, R., Moura, T., } \\
\text { Santana, L. O. }\end{array}$ & 4 & 2018 & ENEGEP \\
\hline $\begin{array}{l}\text { Impacto dos conceitos do MRP no } \\
\text { gerenciamento de estoques numa } \\
\text { empresa metalúrgica do polo metal- } \\
\text { mecânico da Serra Gaúcha }\end{array}$ & $\begin{array}{c}\text { Menegat, O., Borella, M. R. } \\
\text { C. }\end{array}$ & 2 & 2016 & ENEGEP \\
\hline $\begin{array}{l}\text { Melhoria de processos e controle de } \\
\text { estoques num departamento de uma } \\
\text { instituição de ensino superior pública }\end{array}$ & $\begin{array}{l}\text { Pontes, H. L. J., Rodrigues, } \\
\text { M. S., Verde, L. Q. L., } \\
\text { Costa, P. L. }\end{array}$ & 2 & 2016 & ENEGEP \\
\hline $\begin{array}{c}\text { Gestão de estoques em uma empresa } \\
\text { alimentícia do varejo em Fortaleza-CE: } \\
\text { um estudo de caso }\end{array}$ & $\begin{array}{l}\text { Aguiar, K. W. L., Pontes, } \\
\text { H. L. J., Costa, P. L., } \\
\text { Moraes, T. C., Lima, R. R. }\end{array}$ & 0 & 2015 & ENEGEP \\
\hline $\begin{array}{c}\text { Gestão de estoque e eficiência dinâmica: } \\
\text { uma abordagem integrada entre análise } \\
\text { envoltória de dados (DEA) e teoria do } \\
\text { controle ótimo (OCT) }\end{array}$ & Alves, P. N., Jr. & 2 & 2018 & $\begin{array}{l}\text { Biblioteca Digital } \\
\text { Brasileira de Teses e } \\
\text { Dissertações } \\
\text { (BDTD) }\end{array}$ \\
\hline $\begin{array}{l}\text { Aplicação da curva abc e seu efeito na } \\
\text { acuracidade do estoque em uma empresa } \\
\text { de revenda de kit de embreagem na } \\
\text { região da zona da mata mineira }\end{array}$ & $\begin{array}{l}\text { Pereira, L. C., Fabbis, B. F., } \\
\text { Oliveira, M. C. F., Oliveira, } \\
\text { P. W. S., Abreu, S. R. }\end{array}$ & 0 & 2020 & $\begin{array}{l}\text { Brazilian Journal of } \\
\quad \text { Production } \\
\text { Engineering - BJPE }\end{array}$ \\
\hline $\begin{array}{l}\text { Proposta para melhoria na gestão de } \\
\text { estoque em uma empresa que atua no } \\
\text { setor de distribuição de alimentos do } \\
\text { meio oeste catarinense }\end{array}$ & $\begin{array}{l}\text { Piran, A., Vanin, A. B., } \\
\text { Azzolini, J. C. }\end{array}$ & 0 & 2020 & ENEGEP \\
\hline $\begin{array}{l}\text { Gestão de estoque: eficácia do uso das } \\
\text { ferramentas } 5 \mathrm{~s} \text { e diagrama de Ishikawa }\end{array}$ & $\begin{array}{l}\text { Lucas, G. A., Ferreira, L. G. } \\
\text { M., Ribeiro, A., Gontijo, F. } \\
\text { B. }\end{array}$ & 0 & 2018 & ENEGEP \\
\hline $\begin{array}{l}\text { Benefícios de implementação da } \\
\text { automação no controle de estoque: um } \\
\text { estudo de caso em uma empresa de } \\
\text { mecânica para caminhões }\end{array}$ & $\begin{array}{l}\text { Alves, E. D., Santos, M. P. } \\
\text { S., Paula, T. S. }\end{array}$ & 0 & 2020 & ENEGEP \\
\hline $\begin{array}{l}\text { Previsão de demanda: simulação em uma } \\
\text { empresa do segmento de artigos para } \\
\text { dança, fitness, natação e sportswear }\end{array}$ & $\begin{array}{l}\text { Candeias, T. M., Olivo, A. } \\
\text { M., Lemos, F. K. }\end{array}$ & 0 & 2020 & $\begin{array}{l}\text { Revista Produção } \\
\text { Online }\end{array}$ \\
\hline $\begin{array}{l}\text { Gerenciamento de estoque: } \\
\text { implementação de melhoria em uma } \\
\text { fábrica de vassouras recicláveis }\end{array}$ & $\begin{array}{l}\text { Peluso, E. C. P., Cotrim, S. } \\
\text { L., Oliveira, C. C., Campos, } \\
\text { R. V. M., Cardoza, E. }\end{array}$ & 0 & 2020 & ENEGEP \\
\hline $\begin{array}{l}\text { Melhoria no controle de estoque em uma } \\
\text { indústria de velas no vale do paraíba }\end{array}$ & $\begin{array}{l}\text { Mantovani, M. S., Silva, B. } \\
\text { M. B., Pirtouscheg, A. L. } \\
\text { O., Pascoal, E. T., } \\
\text { Evangelista, B. M. C. }\end{array}$ & 0 & 2020 & ENEGEP \\
\hline $\begin{array}{l}\text { Proposta de um controle de estoque em } \\
\text { uma empresa do ramo alimentício }\end{array}$ & $\begin{array}{l}\text { Moraes Filho, J. R. S., } \\
\text { Pereira, F. A., Teixeira } \\
\text { Filho, J. V. }\end{array}$ & 0 & 2020 & SIMPEP \\
\hline $\begin{array}{l}\text { Planejamento e controle de estoques: um } \\
\text { fator competitivo em micro e pequenas } \\
\text { empresas }\end{array}$ & $\begin{array}{l}\text { Jeronimo, A., Gayer, J. A. } \\
\text { C. A., Tamachiro, T. S. O., } \\
\text { Oliveira, F. R., Marques, } \\
\text { M. A. M. }\end{array}$ & 0 & 2020 & ENEGEP \\
\hline $\begin{array}{l}\text { Análise integrada para a tomada de } \\
\text { decisão: os efeitos da modelagem no } \\
\text { gerenciamento de estoques e o impacto } \\
\text { sobre o indicador de rentabilidade ROI }\end{array}$ & $\begin{array}{l}\text { Vargas, E. J., Baccin, B., } \\
\text { Sellitto, M. A. }\end{array}$ & 2 & 2017 & $\begin{array}{l}\text { Revista Produção } \\
\text { Online }\end{array}$ \\
\hline
\end{tabular}


Citação (APA): Giacomin, C., Gomes, T. C., \& Servare Junior, M. W. J. (2021). Controle de estoques como diferencial estratégico: uma análise bibliométrica por meio do Proknow-C. Brazilian Journal of Production Engineering, 7(3), 41-55.

\section{PROKNOW-C: ANÁLISES}

\section{ANÁLISE BIBLIOMÉTRICA DO PORTFÓLIO}

Dos 16 artigos finais considerados relevantes para o nosso portfólio bibliográfico, foram feitas as seguintes análises:

a) Relevância do artigo perante a quantidade de citações encontrada no Google Scholar, analisada na Figura 3. Nela contém os 6 artigos de maior relevância do portfólio, sendo o artigo de maior relevância "Previsão de demanda e análise simplificada da gestão de estoque aplicadas a uma empresa do setor alimentício" publicado no Brazilian Journal of Production Engineering - BJPE.

Figura 3. Relevância dos artigos do portfólio bibliográfico



b) Revistas/Congressos onde os artigos foram publicados que mais se repetem podem ser observados na Figura 4 em forma gráfica. Nota-se que a maior parte dos artigos, mais de $60 \%$, são artigos publicados no ENEGEP.

Figura 4. Número de artigos por periódicos do portfólio bibliográfico
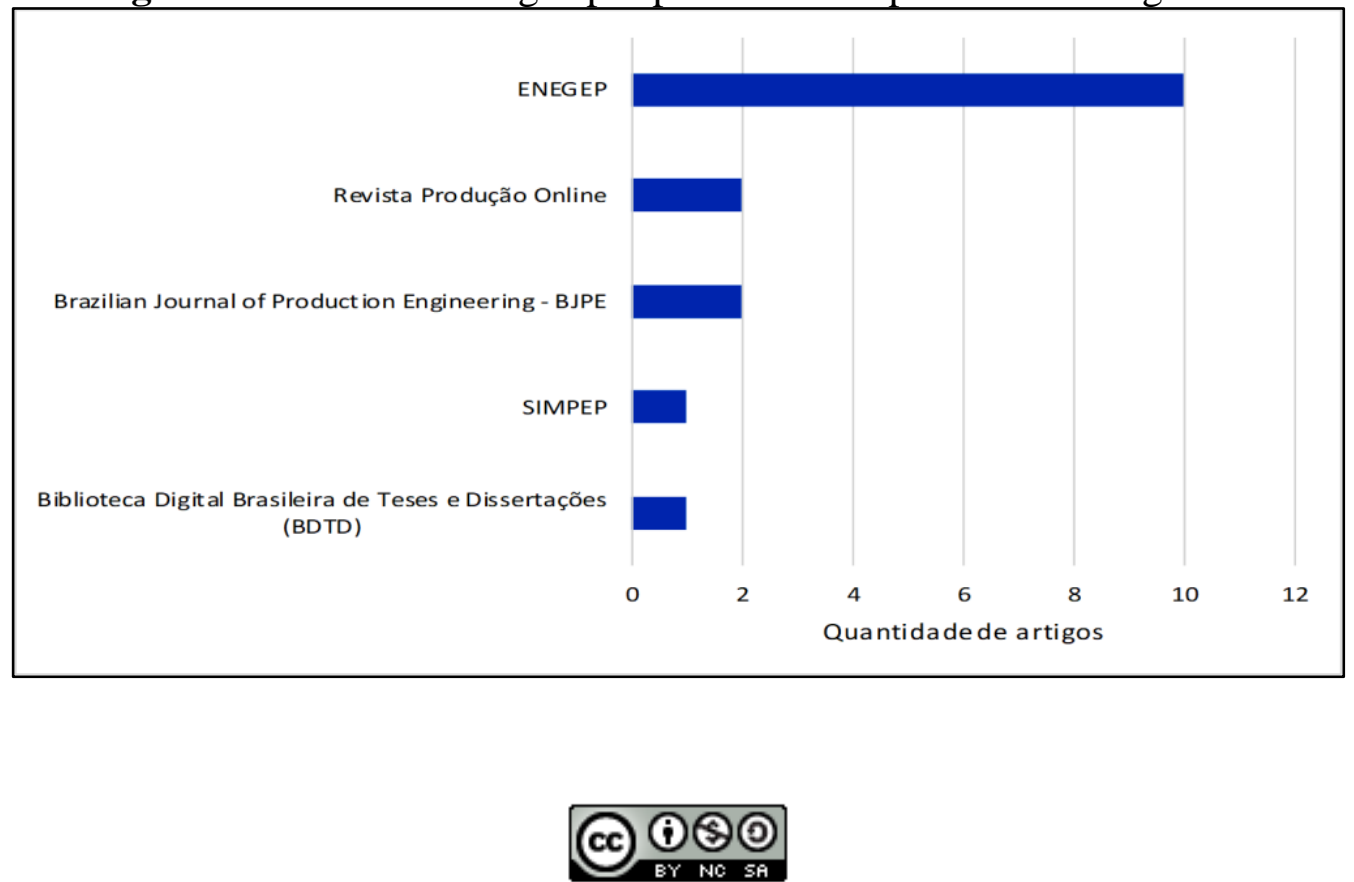

análise bibliométrica por meio do Proknow-C. Brazilian Journal of Production Engineering, 7(3), 41-55.

c) Relevância dos autores observado na Figura 5 através da quantidade de artigos que o autor aparece no portfólio. Nota-se que dois autores do portfólio é autor de dois artigos. Sendo eles autores dos mesmos dois artigos, "Melhoria de processos e controle de estoques num departamento de uma instituição de ensino superior pública" e "Gestão de estoques em uma empresa alimentícia do varejo em Fortaleza-CE: um estudo de caso".

Figura 5. Relevância dos Autores do portfólio bibliográfico

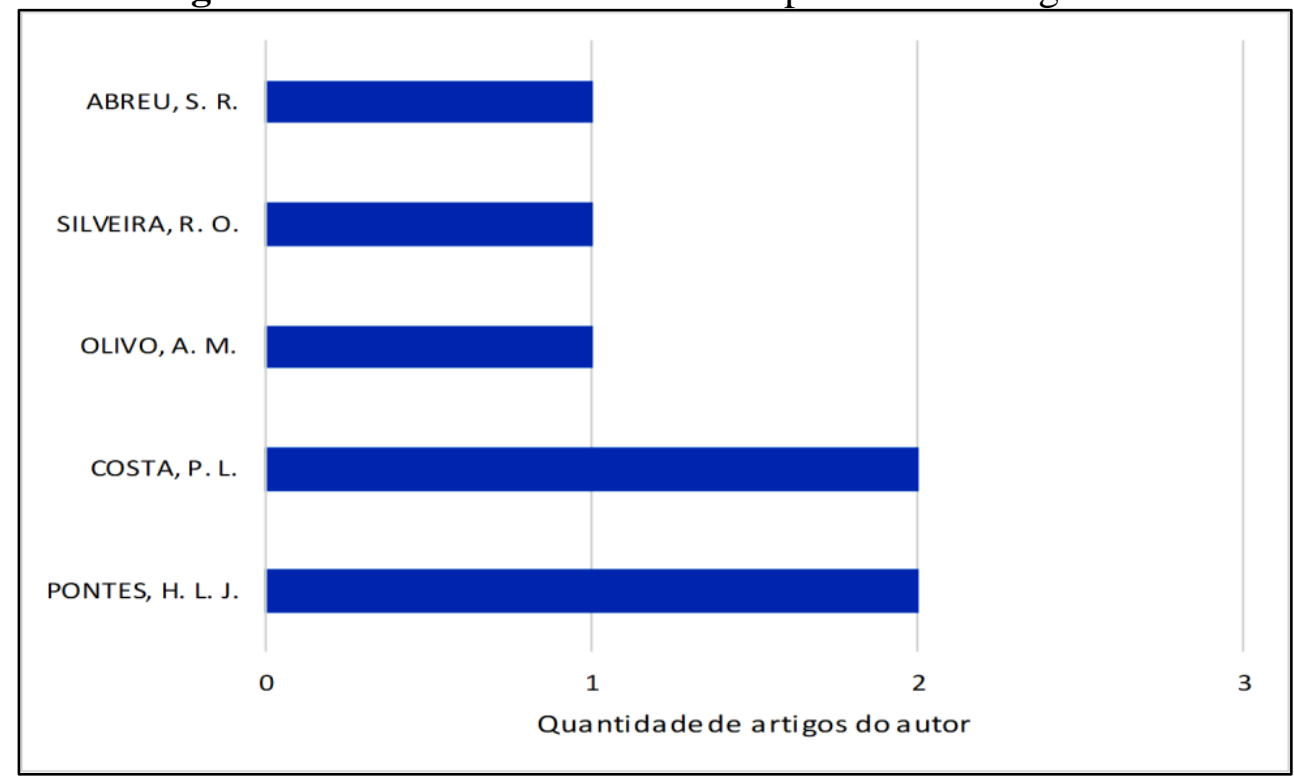

d) Quantidade de artigos por ano observado na Figura 6. Onde 50\% dos artigos do portfólio bibliográfico são do ano de 2020 e $25 \%$ de 2018.

Figura 6. Artigos por ano do portfólio bibliográfico



e) Relevância dos autores das referências, observado na Figura 7. Onde, como autor mais relevante, encontra-se o Cooper, tendo sido citado 5 vezes nas referências por seus trabalhos. 
Citação (APA): Giacomin, C., Gomes, T. C., \& Servare Junior, M. W. J. (2021). Controle de estoques como diferencial estratégico: uma análise bibliométrica por meio do Proknow-C. Brazilian Journal of Production Engineering, 7(3), 41-55.

Figura 7. Relevância dos autores de referência

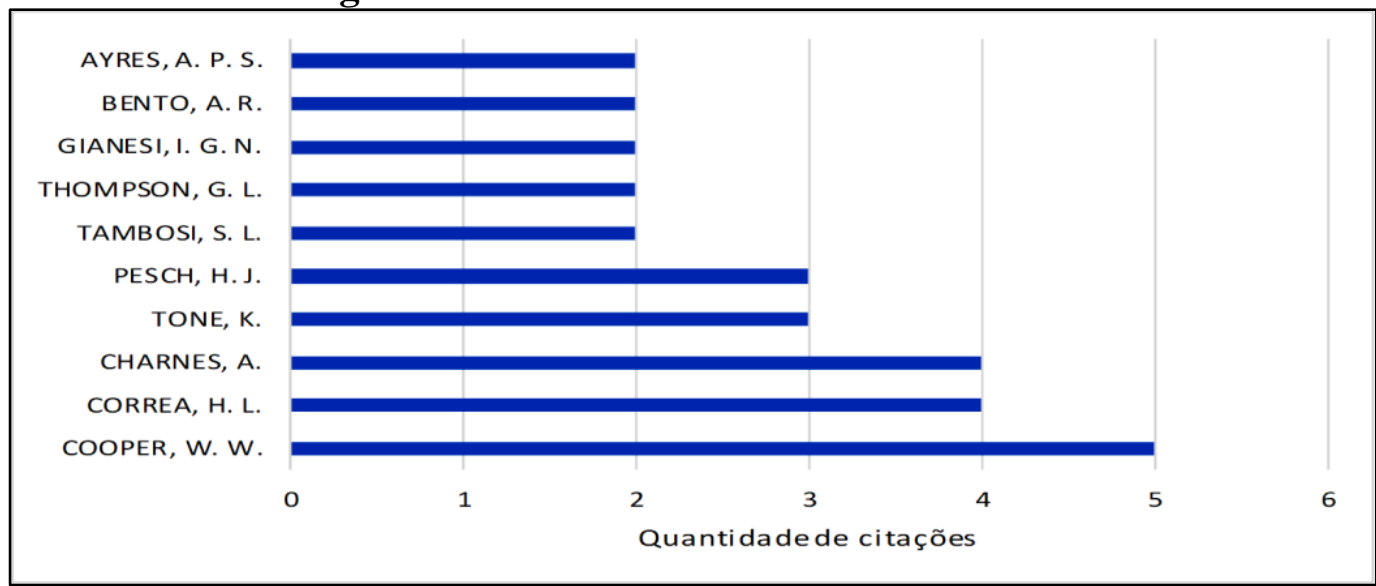

f) Relevância das referências do portfólio, visualizado na Figura 8, onde mostra a quantidade de citações obtida no Google Scholar. Nota-se que as referências do portfólio bibliográfico são trabalhos de grande importância científica, algumas com mais de 50 mil citações.

Figura 8. Relevância das referências do portfólio



g) Número de citações das referências, observado na Figura 9, onde mostra a quantidade de vezes em que um trabalho foi citado nas referências.

Figura 9. Número de citações das referências
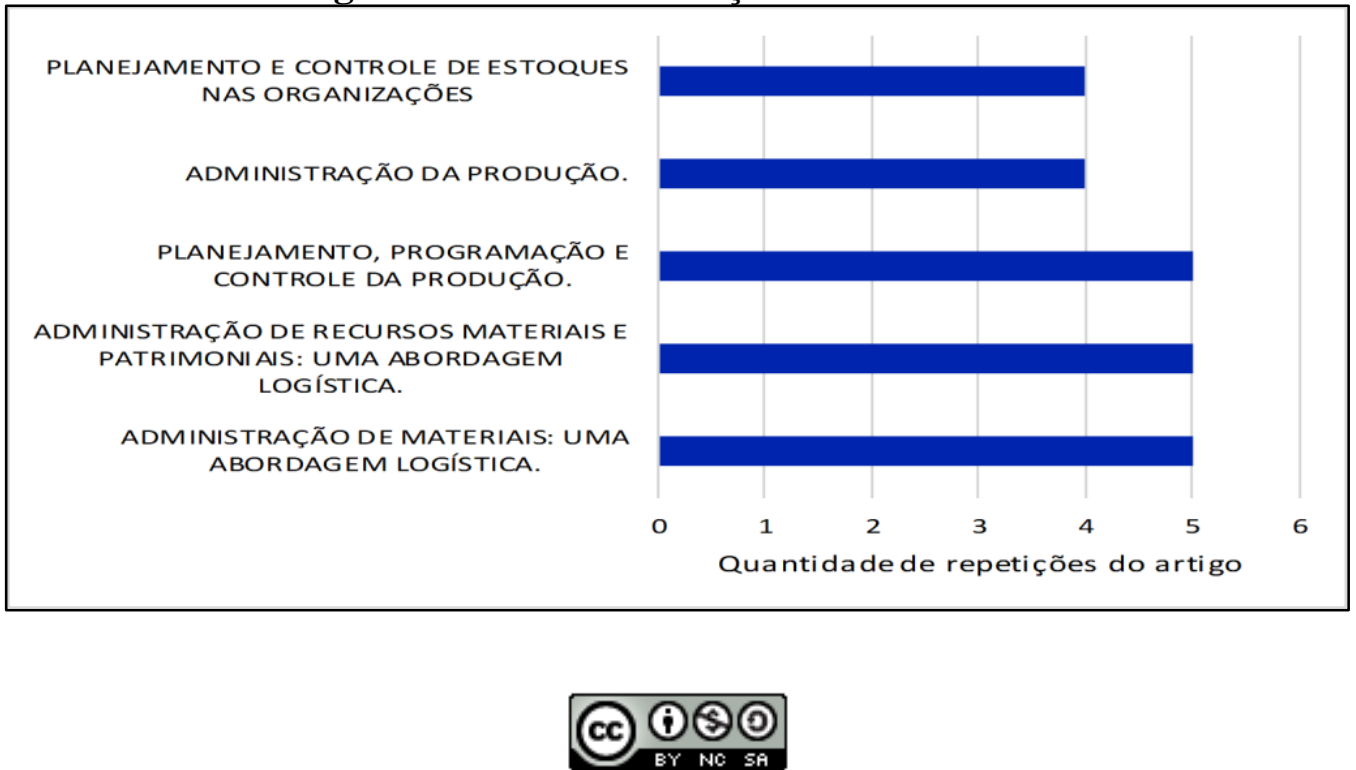

Esta obra está licenciada com uma Licença Creative Commons Atribuição-Não Comercial-Compartilha Igual 4.0 Internacional. Brazilian Journal of Production Engineering, São Mateus, Editora UFES/CEUNES/DETEC. 
Citação (APA): Giacomin, C., Gomes, T. C., \& Servare Junior, M. W. J. (2021). Controle de estoques como diferencial estratégico: uma análise bibliométrica por meio do Proknow-C. Brazilian Journal of Production Engineering, 7(3), 41-55.

Os artigos de destaque, levando em consideração a quantidade de citações do Google Scholar e se o autor desse artigo foi citado nas referências, podem ser visualizados na Figura 10. Nela, encontra-se uma relação dessas informações mostrando os artigos mais relevantes (descritos no Quadro 1) do portfólio bibliográfico selecionado.

Figura 10. Artigos de destaque

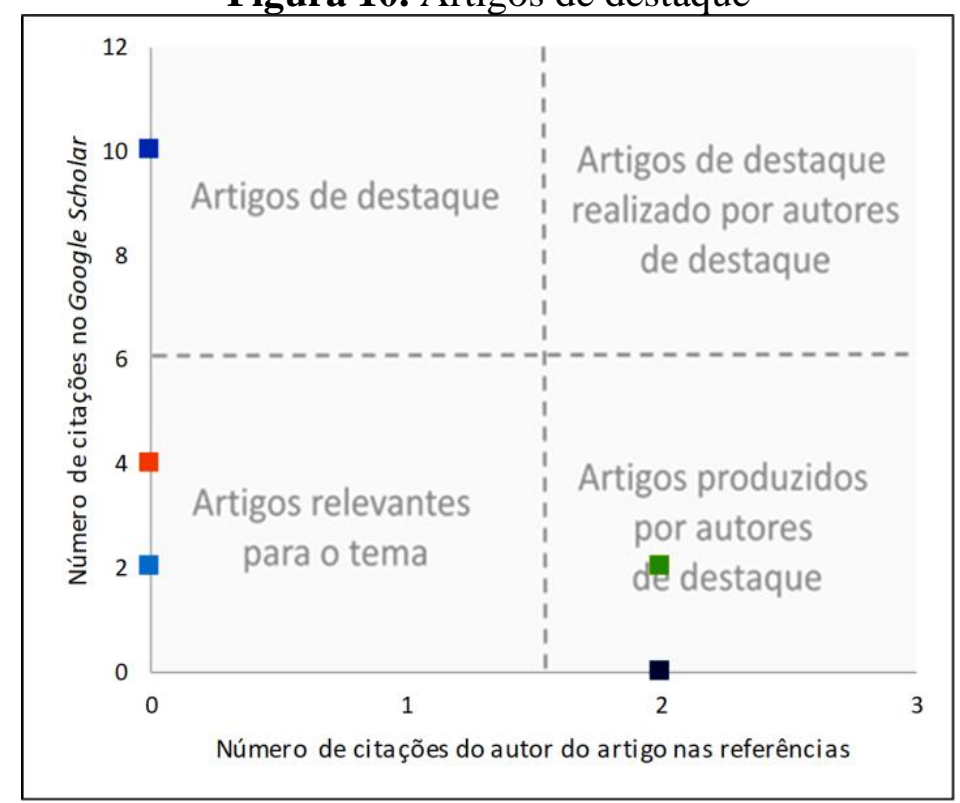

Nota-se que não houve artigos no quadrante Artigos de destaque realizado por autores de destaque, por outro lado, temos um artigo no quadrante Artigos de destaque com alto número de citações. E temos também artigos enquadrados no quadrante Artigos produzidos por autores de destaque. Há artigos com as mesmas cores na coluna "Cor figura 10", pois eles possuem os mesmos números na Figura 10 representada graficamente.

Quadro 3. Artigos relevantes encontrados a partir da Figura 10

\begin{tabular}{|c|c|c|c|}
\hline \multirow[t]{8}{*}{ Cor Figura 10} & Artigo & Autor (es) & Ano \\
\hline & $\begin{array}{c}\text { Previsão de demanda e análise simplificada da gestão } \\
\text { de estoque aplicadas a uma empresa do setor } \\
\text { alimentício }\end{array}$ & $\begin{array}{l}\text { Araújo, G. C., Silva, J. P. Z., } \\
\text { Souza, L. R., Loureiro, M. B., } \\
\text { Feroni, R. C. }\end{array}$ & 2018 \\
\hline & $\begin{array}{c}\text { Aplicação da curva abc na gestão de estoque de uma } \\
\text { micro empresa de aracaju-se }\end{array}$ & $\begin{array}{l}\text { Palomino, R., Silveira, R. O., } \\
\text { Oliveira, R., Moura, T., Santana, } \\
\text { L. O. }\end{array}$ & 2018 \\
\hline & $\begin{array}{c}\text { Impacto dos conceitos do MRP no gerenciamento de } \\
\text { estoques numa empresa metalúrgica do polo metal- } \\
\text { mecânico da serra gaúcha }\end{array}$ & Menegat, O., Borella, M. R. C. & 2016 \\
\hline & $\begin{array}{c}\text { Análise integrada para a tomada de decisão: os efeitos } \\
\text { da modelagem no gerenciamento de estoques e o } \\
\text { impacto sobre o indicador de rentabilidade ROI }\end{array}$ & $\begin{array}{l}\text { Vargas, E. J., Baccin, B., Sellitto, } \\
\text { M. A. }\end{array}$ & 2017 \\
\hline & $\begin{array}{l}\text { Melhoria de processos e controle de estoques num } \\
\text { departamento de uma instituição de ensino superior } \\
\text { pública }\end{array}$ & $\begin{array}{l}\text { Pontes, H. L. J., Rodrigues, M. } \\
\text { S, , Verde, L. Q. L., Costa, P. L. }\end{array}$ & 2016 \\
\hline & $\begin{array}{l}\text { Gestão de estoque e eficiência dinâmica: uma } \\
\text { abordagem integrada entre análise envoltória de dados } \\
\text { (DEA) e teoria do controle ótimo (OCT) }\end{array}$ & Alves Junior, P. N. & 2018 \\
\hline & $\begin{array}{l}\text { Gestão de estoques em uma empresa alimentícia do } \\
\text { varejo em Fortaleza-CE: um estudo de caso }\end{array}$ & $\begin{array}{l}\text { Aguiar, K. W. L., Pontes, H. L. } \\
\text { J., Costa, P. L., Moraes, T. C., } \\
\text { Lima, R. R. }\end{array}$ & 2015 \\
\hline
\end{tabular}

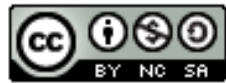


Citação (APA): Giacomin, C., Gomes, T. C., \& Servare Junior, M. W. J. (2021). Controle de estoques como diferencial estratégico: uma análise bibliométrica por meio do Proknow-C. Brazilian Journal of Production Engineering, 7(3), 41-55.

A partir da Figura 10, juntamente com as informações do Quadro 3, verificou-se que no portfólio bibliográfico existem quatro artigos de maior relevância científica, como pode ser observado no Quadro 4. Eles podem ser visualizados nos quadrantes "Artigos de destaques" e "Artigos produzidos por autores de destaques".

Quadro 4. Artigos finais relevantes do portfólio bibliográfico

\begin{tabular}{|c|c|c|c|}
\hline Cor Figura 10 & Artigo & Autor (es) & Ano \\
\hline & $\begin{array}{c}\text { Previsão de demanda e análise simplificada da gestão } \\
\text { de estoque aplicadas a uma empresa do setor } \\
\text { alimentício }\end{array}$ & $\begin{array}{c}\text { Araújo, G. C., Silva, J. P. Z., } \\
\text { Souza, L. R., Loureiro, M. B., } \\
\text { Feroni, R. C. }\end{array}$ & 2018 \\
\hline $\begin{array}{c}\text { Melhoria de processos e controle de estoques num } \\
\text { departamento de uma instituição de ensino superior } \\
\text { pública }\end{array}$ & $\begin{array}{c}\text { Pontes, H. L. J., Rodrigues, M. } \\
\text { S,, Verde, L. Q. L., Costa, P. L. }\end{array}$ & 2016 \\
\hline $\begin{array}{c}\text { Gestão de estoque e eficiência dinâmica: uma } \\
\text { abordagem integrada entre análise envoltória de } \\
\text { dados (dea) e teoria do controle ótimo (oct) }\end{array}$ & Alves Junior, P. N. & 2018 \\
\hline $\begin{array}{c}\text { Gestão de estoques em uma empresa alimentícia do do } \\
\text { varejo em fortaleza-ce: um estudo de caso }\end{array}$ & $\begin{array}{c}\text { Aguiar, K. W. L., Pontes, H. L. Costa, P. L., Moraes, T. C., } \\
\text { Jima, R. R. }\end{array}$ & 2015 \\
\hline
\end{tabular}

\section{ANÁLISE SISTÊMICA DO PORTFÓLIO}

Uma vez que o portfólio foi definido e analisado bibliometricamente, a próxima etapa é a análise sistêmica, que trata o conteúdo dos artigos como um todo. Em relação ao tema, controle de estoque como diferencial estratégico, diversos aspectos podem ser constatados através da literatura. $\mathrm{Na}$ análise sistêmica, serão observados os seguintes fatores de cada trabalho que compõe o portfólio:

I) Contribuição do trabalho para com o tema proposto;

II) O que foi realizado no decorrer de cada trabalho;

III) Se foi efetuado um estudo de caso ou não;

IV) Técnicas e abordagens utilizadas.

Araújo, Silva, Souza, Loureiro e Feroni (2018), através de modelos matemáticos, propôs uma previsão de demanda com a finalidade de um controle melhorado das incertezas da demanda e obter, assim, uma boa previsão da mesma. A partir e em conjunto desse estudo, foi realizado também uma análise simplificada da gestão de estoque para com a empresa estudo, visto que foi realizado um estudo de caso. Para a previsão de demanda, foram utilizados os dois modelos disponíveis de Holt-Winters, tanto o multiplicativo, quanto o método aditivo de diferentes tamanhos de sazonalidades. Com essa aplicação, a empresa pôde obter um melhor controle dos recursos atendendo futuras demandas.

Para Palomino, Silveira, Oliveira, Moura e Santana (2018), definiu-se, através do estudo de caso aplicado, o quanto deve-se comprar e estocar a fim de obter o controle de estoque desejado. Foi realizada a análise e a aplicação do método da curva ABC em uma empresa de Aracaju/SE. A partir da técnica aplicada, pôde-se reduzir os custos com o estoque, pois através do método utilizado obtém-se a real necessidade de estoque da empresa. No decorrer do trabalho, em vista

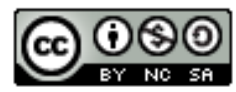



análise bibliométrica por meio do Proknow-C. Brazilian Journal of Production Engineering, 7(3), 41-55.

do método utilizado, foi possível determinar as classes dos produtos em A, B e C de acordo com sua relevância.

Menegat e Borella (2016) propuseram em seu estudo de caso os possíveis ganhos que o método aplicado MRP pode trazer para com o controle e gerenciamento do estoque da empresa. Primeiramente foi abordado os conceitos do método, vantagens e ligação com a Produção Enxuta. Após essa análise, foi definido a metodologia da pesquisa e, em suma, as propostas de melhorias.

Pontes, Rodrigues, Verde e Costa (2016) utilizou da proposta de implantação de melhorias na gestão de estoque. Com isso, foi realizado o levantamento de informações perante a empresa estudada em seu estudo de caso, como estrutura, processos, estoques, entre outros. Através do estudo de caso, aplicou-se técnicas e abordagens como pesquisa de satisfação, gestão de processos de negócio (BPM) e um mapeamento dos processos em geral identificando assim as possíveis melhorias que podem ser aplicadas.

Em paralelo, Vargas et al. (2017) apontam como importante regulador de níveis de serviço e da rentabilidade a gestão de estoque. Além disso, modelaram, através do método de modelagem quantitativa, quatro cenários, onde pode-se comparar diversas informações. Com isso pode-se escolher o melhor cenário dentre os quatro e realizar a aplicação, através de um estudo de caso em uma empresa metal mecânica.

Alves (2018) aplicou o estudo a fim de obter um método eficiente de avaliação da gestão de estoque, através da aplicação da Teoria de Controle Ótimo (OCT) e Análise Envoltória de Dados (DEA), obtendo assim através dessas aplicações, respectivamente, a estocagem ótima e o cálculo de eficiência relativa. Através dessas aplicações, desenvolveu um modelo integrado DEA-OCT.

Aguiar, Pontes, Costa, Moraes e Lima (2015) mostram através de um estudo de caso a aplicação do gerenciamento de estoque em uma empresa de varejo do ramo alimentício. De acordo com a classificação do método $\mathrm{ABC}$, escolheu-se os produtos de venda direta de maior faturamento para aplicar, em cima desse grupo de produtos, o gerenciamento de estoque. Após o estudo, notou-se uma redução de gastos nos lotes de aproximadamente $6,25 \%$, constatando que, além de melhorar o nível de serviço, o gerenciamento de estoque quando aplicado corretamente também traz economia.

Lucas et al. (2018) apresentam a eficiência da gestão de estoque através das ferramentas sugeridas por eles, 5S e Diagrama de Ishikawa. Foi realizado um estudo de casos aplicado a ao almoxarifado de uma empresa de beneficiamento de sementes. Utilizaram-se do método de pesquisa de campo por 2 meses corridos onde pode-se detectar lacunas. Após a aplicação das duas ferramentas perante as lacunas encontradas, notou-se uma melhoria no controle de estoque juntamente com a melhoria na rotina dos funcionários.

Alves, Santos e Paula (2020) desenvolveram um estudo de caso de caráter observatório e análise qualitativa, juntamente com uma pesquisa bibliográfica, a observação e análise do sistema existente na empresa, com o objetivo de identificar e reportar os benefícios da automação do

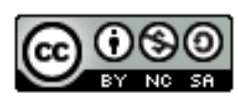



análise bibliométrica por meio do Proknow-C. Brazilian Journal of Production Engineering, 7(3), 41-55.

controle de estoque. $\mathrm{O}$ estudo de caso foi aplicado no setor de estoque de uma oficina mecânica através da realização e prática do software ERP (Planejamento de Recursos Empresariais).

Candeias, Olivo e Mendes (2020) realizou o trabalho com o intuito de avaliar e escolher qual o método de previsão de demanda mais eficaz através da simulação. Sendo que, como melhor método, sobressaiu-se, através da simulação, o método de Suavização Exponencial com Tendência e Sazonalidade - Método de Holt-Winters.

Peluso et al. (2020), através de um estudo de caso, implementou melhorias no processo de gerenciamento de estoque em uma fábrica através do método Kanbam com a proposta de obter um estoque suficiente para a produção e sua demanda. Com uma abordagem qualitativaquantitativa, a pesquisa realizou diversos levantamentos, por exemplo o cálculo de estoque de segurança para então realizar a aplicação do método proposto.

Do mesmo modo, Mantovani, Silva, Pirtouscheg, Pascoal e Evangelista (2020) propuseram uma melhoria na gestão de estoque através de um estudo de caso em uma indústria usando também da aplicação do método Kanbam utilizando das ferramentas curva ABC e gráfico dente de serra e aplicou, além disso, uma reorganização do layout, o que possibilitou um melhor controle de estoque evitando diversos contratempos e agilizando vários procedimentos.

Através de um estudo de caso, Pereira, Teixeira e Moraes (2020) propuseram, em uma empresa do ramo alimentício, aplicar uma gestão de estoque, visto que a empresa estava com alto índice de acumulo de mercadoria no almoxarifado.

Por meio da ferramenta de curva ABC, Pereira, Fabbis, Oliveira, Oliveira e Abreu (2020), estudaram o efeito que a ferramenta produziu na acuracidade do estoque. Em seu estudo de caso, foram observados através de uma revisão bibliográfica, as necessidades para gerar o estudo da ferramenta proposta. Após isso, foi feito estudos in loco para aplicação da mesma. $\mathrm{O}$ que ocasionou uma visível melhora após implementação.

Piran, Azzolini e Vanin (2020) também propuseram uma melhora na gestão de estoque como métrica para diminuição dos custos ocasionando um maior lucro sem precisar de aumentar o preço repassado ao cliente. Foi utilizada a classificação ABC, calculado o estoque de segurança dos produtos e a aplicação do Kanbam o que levou à redução do índice de falta de produto.

Jeronimo, Gayer, Tamachiro, Oliveira e Marques (2020) buscaram, através de entrevistas com empresários, descobrir quais eram os pontos negativos que eles gostariam que fossem tratados em relação à gestão de estoque que poderiam ser resolvidos com ferramentas da gestão de estoque, evidenciando de que forma as empresas podem se tornar competitivas.

\section{CONSIDERAÇÕES FINAIS}

O presente artigo obteve sucesso ao atingir os objetivos gerais e específicos de forma gradativa, conforme apresentado. Pode-se notar o grande número de informações relevantes consideradas ao longo do artigo de acordo com o do tema proposto, Controle de estoque como diferencial estratégico. A partir da aplicação do método ProKnow-C, foi alcançado um portfólio bibliográfico com 16 artigos de grande relevância científica e alinhados ao tema da pesquisa. Para alcançar esse resultado, foi feita uma pesquisa da palavra-chave "Controle de Estoque",

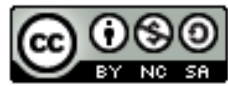



análise bibliométrica por meio do Proknow-C. Brazilian Journal of Production Engineering, 7(3), 41-55.

definida previamente, por meio dessa pesquisa, gerou-se o banco de artigos e, posteriormente, a aplicação de diversos filtros nesse banco de artigos.

De posse desses resultados, realizou-se um estudo quantitativo e qualitativo do portfólio bibliográfico onde foi possível visualizar diversas informações importantes, a listar: o periódico mais citado foi o canal Anais ENEGEP, com 10 artigos finais no portfólio; o artigo com maior relevância acadêmica "Previsão de demanda e análise simplificada da gestão de estoque aplicadas a uma empresa do setor alimentício", com 10 citações do Google Scholar; Pontes e Costa como autores mais citados no portfólio, com duas citações cada; e 2020 sendo o ano com mais publicações encontradas, com 8 artigos nesse ano.

Com esses processos finalizados, pôde-se perceber que o método ProKnow-C auxilia na busca de artigos relevantes quando o pesquisador necessita de um portfólio bibliográfico organizado e com boa estrutura para assim encontrar as informações necessárias relevantes para o tema proposto. Nota-se também que o tema proposto é discutido amplamente em diversas regiões brasileiras e internacionais, ocasionando um amplo setor de busca.

\section{REFERÊNCIAS}

Aguiar, K. W. L. de, Pontes, H. L. J., Costa, P. L., Moraes, T. de C., \& Lima, R. R. (2015) Gestão de estoques em uma empresa alimentícia do varejo em Fortaleza,CE: um estudo de caso. Anais do Encontro Nacional de Engenharia de Produção, Enegep. Fortaleza, CE, Brasil, 35.

Alves, E. de D., Santos M. P. da S., \& Paula, T. dos S. (2020) Benefícios de implementação da automação no controle de estoque: Um estudo de caso em uma empresa de mecânica para caminhões. Anais do Encontro Nacional de Engenharia de Produção, Enegep. Foz do Iguaçu, PR, 40 .

Alves, P. N., Jr. (2018). Gestão de estoque e eficiência dinâmica: Uma abordagem integrada entre Análise Envoltória de Dados (DEA) e Teoria do Controle Ótimo (OCT). Tese (Doutorado), Universidade de São Paulo, São Paulo, SP, Brasil. Recuperado de http://bdtd.ibict.br/vufind/Record/USP 9d58154f0e25b9a4a04827c8868b48df/Details

Araujo, G. C., Silva, J. P. Z. da, Souza, L. R., Loureiro, B. M., \& Feroni, R. de C. (2018) Previsão de demanda e análise simplificada da gestão de estoque aplicada a uma empresa do setor alimentício. Brazilian Journal of Production Engineering, 4(2), 48-64.

Ballou, R. H. (1993). Logística Empresarial: Transportes, administração de Materiais e Distribuição Física. São Paulo: Atlas.

Ballou, R. H. (2001). Gerenciamento da cadeia de suprimentos: planejamento, organização e logística empresarial. Porto Alegre: Bookman.

Ballou, R. H. (2009). Gerenciamento da Cadeia de Suprimentos/Logística empresarial. (5a ed.) São Paulo: Bookman.

Candeias, T. M., Olivo, A. de M., \& Lemos, F. K. (2020) Previsão de demanda: simulação em uma empresa do segmento de artigos para dança, fitness, natação e sportswear. Revista Produção Online. 20(1), 119-148. http://dx.doi.org/10.14488/1676-1901.v20i1.3343

Ching, H. Y. (2010). Gestão de Estoques na cadeia de logística integrada: supply chain. São Paulo: Atlas.

Chopra, S., \& Meindl, P. (2004). Gerenciamento da cadeia de suprimentos: estratégia, planejamento e operação. ( $3^{\mathrm{a}}$ ed.) Brasil: Pearson Education do Brasil. 
Citação (APA): Giacomin, C., Gomes, T. C., \& Servare Junior, M. W. J. (2021). Controle de estoques como diferencial estratégico: uma análise bibliométrica por meio do Proknow-C. Brazilian Journal of Production Engineering, 7(3), 41-55.

Ensslin, L., Ensslin, S. R., Lacerda, R. T. O., \& Tasca, J. E. (2010). ProKnow-C, Knowledge Development ProcessConstructivist. Processo técnico com patente de registro pendente junto ao INPI. Brasil.

Jeronimo, A., Gayer, J. A. C. A., Tamachiro, T. S. O., Oliveira, F. R. de, \& Marques, M. A. M. (2020) Planejamento e controle de estoques: um fator competitivo em micro e pequenas empresas. Anais do Encontro Nacional de Engenharia de Produção, Enegep. Foz do Iguaçu, PR, 40.

Lucas, G. A., Ferreira, L. G. M., Ribeiro, A., \& Gontijo, F. de B. (2018) Gestão de estoque: eficácia do uso das ferramentas 5s e diagrama de Ishikawa. Anais do Encontro Nacional de Engenharia de Produção, Enegep. Maceió, AL, 38.

Mantovani, M. S., Silva, B. M. B. da, Pirtouscheg, A. L. O., Pascoal, E. T., \& Evangelista, B. M. de C. (2020) Melhoria no controle de estoque em uma indústria de velas do vale do paraíba. Anais do Encontro Nacional de Engenharia de Produção, Enegep. Foz do Iguaçu, PR, 40.

Menegat, O., \& Borella, M. R. de C. (2016) Impacto dos conceitos do mrp no gerenciamento de estoques numa empresa metalúrgica do polo metal-mecânico da serra gaúcha. Anais do Encontro Nacional de Engenharia de Produção, Enegep. João Pessoa, PB, 36.

Novaes, A. G. N. (2004) Logística e Gerenciamento da Cadeia de Distribuição. Rio de Janeiro: Campus.

Palomino, R., Silveira, R. O., Oliveira, R., Moura, T., \& Santana, L. O. de. (2018) Aplicação da curva abc na gestão de estoque de uma micro empresa de Aracaju - SE. Anais do Encontro Nacional de Engenharia de Produção, Enegep. Maceió, AL, 38.

Peluso, E. C. P., Cotrim, S. L., Oliveira, C. C. de, Campos, R. V. de M., \& Galdamez, E. V. C. (2020) Gerenciamento de estoque: implementação de melhoria em uma fábrica de vassouras recicláveis. Anais do Encontro Nacional de Engenharia de Produção, Enegep. Foz do Iguaçu, PR, 40.

Pereira, F. A., Teixeira, J. V., Filho, \& Moraes, J. R. S., Filho. (2020) Proposta de um controle de estoque em uma empresa do ramo alimentício. Anais Simpósio de Engenharia de Produção, SIMPEP. Baurú, SP, 27.

Pereira, L. C., Fabbis, B. F., Oliveira, M. C. F. de, Oliveira, P. W. C. de, \& Abreu, S. R. de. (2020). Aplicação da curva abc e seu efeito na acuracidade do estoque em uma empresa de revenda de kit de embreagem na região da zona da mata mineira. Brazilian Journal of Production Engineering, 6(7), 58-67. https://doi.org/10.47456/bjpe.v6i7.32837

Pinto, R. A. Q., Tortato, U., Veiga, C. P. da, \& Catapan, A. (2013) Gestão de estoque e lean manufacturing: estudo de caso em uma empresa metalúrgica. Revista Administração em Diálogo, São Paulo, 15(1), 111-138. https://doi.org/10.20946/rad.v15i1.12095

Piran, A., Azzolini, J. C., \& Vanin, A. B. (2020) Proposta para Melhoria na Gestão de Estoque em uma Empresa que Atua no Setor de Distribuição de Alimentos do Meio Oeste Catarinense. Anais do Encontro Nacional de Engenharia de Produção, Enegep. Foz do Iguaçu, PR, 40.

Pontes, H. L. J., Rodrigues, M. S., Verde, L. Q. L., \& Costa, P. L. (2016) Melhoria de processos e controle de estoques num departamento de uma instituição de ensino superior pública. Anais do Encontro Nacional de Engenharia de Produção, Enegep. João Pessoa, PB, 36.

Pozo, H. (2001). Administração de recursos materiais e patrimoniais: uma abordagem logística. São Paulo: Atlas.

Vargas, E. J. de, Baccin, B., \& Sellitto, M. A. (2017) Análise integrada para a tomada de decisão: os efeitos da modelagem no gerenciamento de estoques e o impacto sobre o indicador de rentabilidade ROI. Revista Produção Online, Florianópolis, 17(1), 325-350. http://dx.doi.org/10.14488/1676-1901.v17i1.2556

Viana, J. J. (2000) Administração de Materiais: um enfoque prático. São Paulo: Atlas. 